\title{
INFANCIA ESCOLARIZADA EN ZONAS RURALES DE LA COSTA DE CHIAPAS: CONDICIONES DE CENTROS EDUCATIVOS PREESCOLARES
}

\section{Childhood in Rural Schools along the Coast of Chiapas: Conditions of Preschool Education Centers}

\author{
Martín Plascencia-González* \\ Kathia Núñez-Patiño**
}

DOI: http://dx.doi.org/10.29043/liminar.vl8il.723

\begin{abstract}
Resumen: En el marco de los estudios de las infancias y su diversidad, abordando en particular la primera infancia escolarizada en contextos rurales, se desarrolló una investigación en la zona costa de Chiapas, México, para conocer la situación de instituciones que atienden infancia desde la perspectiva de los actores formadores: docentes y directivos. Los datos recolectados provienen de centros preescolares generales, Centros de Educación Comunitaria del Consejo Nacional de Fomento Educativo (CONAFE) y un Centro de Desarrollo Infantil. Se presentan resultados de las condiciones físicas, de formación, legales y de atención de dichas instituciones y se discuten los resultados en el marco de la infancia escolarizada y la marginación de la educación en contextos rurales.
\end{abstract}

Palabras clave: primera infancia; escolarización; escuelas rurales; educación de la primera infancia; personal educativo.

Abstract: In research on the diversity of childhood studies and those that addressed early childhood in rural contexts in particular, I examined the situation of primary schooling along the coastal area of Chiapas from the point of view of teachers and administrative staff. The data collected comes from preschools, Community Education Centers run by the National Council of Educational Development (CONAFE), and a Child Development Center (CDI). I review the results of the physical, training, legal, and care conditions of these schools and discuss these in the context of childhood schooling and the marginalization of education in rural contexts.

Keywords: early childhood; schooling; rural schools; early childhood education; educational personnel.

\footnotetext{
* Martín Plascencia González. Doctor en Desarrollo, Aprendizaje y Educación por la Universidad Autónoma de Madrid y la Universidad Nacional de Educación a Distancia de España. Profesor-investigador de la Universidad Autónoma de Chiapas, México. Temas de especialización: infancias, desarrollo moral, bullying y violencia escolar. Correo electrónico: martin.plascencia@unach.mx. ORCID: https:/ orcid.org/0000-0002-9882-9954

* Kathia Núñez Patiño. Doctora en Investigación Educativa por la Universidad Veracruzana, México. Profesora-investigadora de la
}

Universidad Autónoma de Chiapas, México. Temas de especialización: antropología de la educación, infancias, educación autónoma. Correo electrónico: ktyeel@hotmail.com. ORCID: https://orcid.org/00000002-0321-9572

Enviado a dictamen: 28 de mayo de 2019.

Aprobación: 21 de octubre de 2019.

Revisiones: 2. 
La educación inicial y preescolar en el nacimiento del sistema educativo formal nacional

L a política gubernamental en torno a la infancia está enfocada en garantizar derechos, entre los cuales se encuentra el derecho a la educación (UNICEF, 2013; SEP, 2015). Desde esa política aplicada en México, lo anterior conlleva una responsabilidad pública para la atención y la garantía de educación universal para quienes habiten en el territorio nacional. La educación formal, traducida en procedimientos, niveles y formas, ha sido adoptada por la escuela, que se ha posicionado como un lugar de socialización privilegiado para la población joven en sociedades occidentales. En México se han creado escuelas para atender a la población en una organización etaria: de 3 a 5 años, preescolar; de 6 a 11 años, primaria; de 12 a 14 años, secundaria, de 15 a 17 años, educación media superior, y posteriormente la universidad.

Ahora bien, la escuela como institución requiere ser constantemente estudiada. Se trata de un espacio donde la población joven pasa gran parte del tiempo, que tiene un impacto en el desarrollo humano y en la posición social de quienes reciben la educación, por lo que se debe investigar qué ocurre en los centros donde está institucionalizada la infancia. En este trabajo se parte de la pregunta: iqué está ocurriendo al interior de instituciones donde se atiende a infancia?, ¿cómo describen la situación educativa/atención los actores formadores?, ¿cómo son las condiciones en las que se encuentra la infancia? El interés por ampliar el conocimiento respecto a estas preguntas nos hizo diseñar el proyecto "Evaluación integral de estancias infantiles, centros de atención infantil y preescolares de la zona costa de Chiapas", financiado por el Fondo Sectorial de Investigación para la Evaluación de la Educación, del Consejo Nacional de Ciencia y Tecnología (CONACyT) y el Instituto Nacional para la Evaluación de la Educación (INEE), número 289338. Este proyecto se aboca a la primera infancia, etapa que comprende los primeros seis años de vida. La política educativa dirigida a este grupo de edad busca favorecer entornos seguros y estimulantes para un desarrollo pleno, que integra aspectos físicos, emocionales, cognitivos y sociales (UNICEF, 2013; INEE, 2019; SEP, 2015).

En México se creó la Secretaría de Educación Pública (SEP) en el año 1921, después de la Revolución. Ahora bien, el proceso de escolarización en educación inicial y preescolar ha ido incrementando desde entonces, según el recuento que hace el INEE (2015) retomando datos del Instituto Nacional de Estadística y Geografía (INEGI) y del Consejo Nacional de Población (CONAPO) ordenados según las presidencias nacionales de gobierno. El incremento poblacional de México de 1921 a 2012 fue rápido. De la época de la presidencia de Álvaro Obregón -19211924- cuando inició la SEP, no se tiene registro de la cantidad de docentes ni de alumnos inscritos en este nivel educativo; durante la presidencia de Plutarco Elías Calles la cantidad de alumnos era de 11623 en el año 1925 y de 15845 en 1928. En cuanto al número de docentes solo se cuenta con registros hasta la época de Manuel Ávila Camacho (1941-1946): en el año 1946 había 2080 docentes y 70060 alumnos. En el año 2012, siendo presidente Felipe Calderón, había 4761466 alumnos y 226063 docentes.

En el ciclo escolar 2017-2018, la matrícula de preescolar ascendía a 4891002 alumnos, atendidos por 238153 docentes en 89579 escuelas. Según el tipo de sostenimiento se agrupan en: Centro de Desarrollo Infantil (CENDI) (59 612, 1.2\% alumnos; 2 707, 1.1\% docentes; $966,1.1 \%$ escuelas), general (3 $512731,71.8 \%$ alumnos; 149 688, 62.9\% docentes; 44 963, 50.2\% escuelas), indígena (412 177, 8.4\% alumnos; 19 066, 8.0\% docentes; 9 796, 10.9\% escuelas), comunitario (155 457, 3.2\% alumnos; $19670,8.3 \%$ docentes; $17849,19.9 \%$ escuelas) y privado (751 025, 15.4\% alumnos; $47022,19.7 \%$ docentes; $16005,17.9 \%$ escuelas) (INEE, 2019).

Como se observa, gran parte de la población infantil de entre 3 y 5 años está inscrita en la escuela. El asunto crucial en este punto es que no se conoce a profundidad lo que ocurre en los centros que atienden infancia, pues de manera adicional a los centros preescolares se encuentran otros como las estancias infantiles, los centros de acogida, los centros médicos públicos y privados que atienden 
infancia con consulta interna o externa o las cárceles. En este texto abordaremos solo lo relacionado con infancia escolarizada, es decir, la que asiste a instituciones cuyo quehacer central es educativo.

Los servicios de educación ofrecidos en Chiapas se relacionan con el lugar donde se ofertan. En este sentido, existen todas las modalidades educativas como en el resto del país: comunitaria, indígena unitaria, rural unitaria, rural no unitaria, urbana pública y CENDI.

\section{Estudiar la infancia}

La investigación en infancia es uno de los tópicos emergentes y de gran empuje a nivel mundial en el ámbito académico en diversas áreas del conocimiento. Particularmente, en las ciencias sociales, humanas y de la conducta interesa observar la agentividad de la infancia, la posición social y las concepciones que se depositan sobre la misma, los lugares que habita, las actividades que hacen los niños y niñas y lo que se hace con ellos, las formas en que son vulnerados o resiliencia, sus interacciones, procesos de desarrollo, aprendizaje y otros temas. Aunque la discusión sobre estos aspectos con este acercamiento es novedosa, los estudios centrados en los derechos, responsabilidades y agencia son cuestionados pues se considera que deben tomarse en cuenta otros conceptos centrales en la agenda de investigación sobre la infancia, como los de relaciones y reciprocidad (Tisdall y Punch, 2012), pues la agencia implica un abordaje individual, y se considera que el desarrollo ocurre en el contexto, por lo que es relacional. Tisdall y Punch atraen los estudios de Vygotsky y Rogoff ${ }^{1}$ sobre la importancia de las relaciones para el aprendizaje. Es decir, en el sentido más radical no se puede entender la individualidad sin sus procesos relacionales y los contextos socioculturales en los que se estructura.

Estas discusiones emanan de un considerable incremento de investigaciones en la última década, en un proceso de expansión de las experiencias de investigación con infancias en contextos diversos, sobre todo en los contextos indígenas, afrodescendientes y rurales. De acuerdo con Ayora y Medina:
[...] este proceso de expansión de las experiencias investigativas con infancias indígenas es producto, tanto de un posicionamiento político académico, como de las repercusiones de los movimientos epistémicos cuya genealogía se sustenta en claves como: 1) las movilizaciones y exigencias de reivindicación de los pueblos originarios en Latinoamérica y México; 2) el desarrollo por más de dos décadas de programas y proyectos de carácter intercultural, entre ellos los destinados a la formación de docentes y a la construcción de currículos denominados de igual manera interculturales (Ayora y Medina, 2016:51).

De acuerdo con las autoras, este proceso de expansión impacta en dos ejes que confluyen: la discusión sobre la mirada hegemónica sobre la infancia y los cuestionamientos a la investigación clásica.

La agenda contemporánea de investigación está compuesta de manera más recurrente por aproximaciones inter o transdiciplinarias (James, 2010). Parte de los argumentos que se esgrimen para el abordaje interdisciplinario -epistemológico, metodológico y conceptual - es que la complejidad de los problemas estudiados se puede tratar mejor desde un enfoque múltiple, ya que los problemas no tienen fronteras exclusivas de una disciplina, porque la interacción entre disciplinas puede dar respuestas más innovadoras e integrales a los problemas y el reflexionar con la ayuda de otras disciplinas puede servir para replantear los propios intereses investigativos. ${ }^{2}$ Sin embargo, según reflexiona Alanen (2012), aunque los comentarios a favor de la interdisciplinariedad son adecuados, hay ciertas barreras que impiden su concreción. Pueden ser de los siguientes tipos: estructurales, que tienen que ver con la propia definición, concepción y organización de la ciencia en las instituciones; organizacionales, pues varias instituciones privilegian la incentivación por la especialización de los productos científicos y las formas en que se obtienen, o de conocimiento, que tienen que ver con el desconocimiento per se que se tiene del abordaje de uno o varios temas en otros campos disciplinarios. Aunque haya una intencionalidad 
prevista de tratamiento interdisciplinario, las formas y contenidos sobre cómo hacerlo son generalmente desconocidas. Esa obcecación que se observa de otras disciplinas puede entorpecer el planteamiento de acciones conjuntas, obstruir posibles conexiones entre disciplinas o producir malinterpretación entre las partes. Esta idea de fragmentación o lógica de conjunto del abordaje científico es una tarea constante y debe integrarse como parte de la reflexión crítica del quehacer académico.

Ahora bien, este entorno general completo en las ciencias respecto a la interdisciplinariedad es similar en los estudios sobre primera infancia. Aunque las sociedades tienen previstos componentes para educar y criar a su niñez, no todas las infancias tienen esas oportunidades. Preferimos usar el término infancias, mejor que el de infancia, precisamente como una forma de caracterización conceptual de la diversidad presente en ese grupo etario. Lo mismo ocurre con niñez, término con el que aquí nos referimos a las personas que se encuentran en una edad superior a la que abordamos - mayores de seis años- Derivado de ese desequilibrio de oportunidades, gobiernos, personas, instituciones y organizaciones no gubernamentales crean políticas o programas de intervención para lograr que haya mayor equilibrio y desarrollo para la niñez (Meisels y Shonkoff, 2000; UNICEF, 2013; 2018). De antemano, aunque existe una garantía constitucional, jurídica, que ampara a esta población a través del derecho a la infancia, empíricamente hay desigualdades y no se cumple este objetivo. La calidad en los cuidados iniciales a niñas y niños ha mostrado los beneficios en varias áreas del desarrollo socioemocional (Hirozaku et al., 2000), pero hay infantes que están en condiciones de vulnerabilidad, con rezago, marginados o impedidos para obtener esos cuidados iniciales de calidad. De hecho, informes como los de Save the Children (2017) o UNICEF $(2013 ; 2018)$ son desalentadores si observamos que, según sus cálculos, México ocupa uno de los primeros lugares a nivel mundial en cuanto a abuso infantil, violencia física y homicidio en menores de 14 años. Asimismo, millones de niñas y niños han dejado de vivir su infancia tempranamente, es decir, no viven en contextos acordes a su desarrollo. Hay que hacer notar que los cuidados, la protección y la atención no se refieren en exclusiva a los proporcionados institucionalmente - por ejemplo en estancias infantiles o escuelas preescolares - sino, en general, a la retroalimentación recibida por la infancia en los contextos social, familiar, comunitario, institucional y gubernamental.

La atención y el cuidado infantil, al ser tan importantes para el desarrollo humano, deben observarse continuamente desde la investigación educativa. Entre los estudios que se han realizado en México sobre aspectos educativos de la niñez temprana se encuentra el de Hirozaku et al. (2000) sobre cobertura, calidad y equidad, debido a las reformas en educación básica durante la primera década del siglo XX; en cuanto al nivel preescolar, destacan los estudios de Pérez (2010), de Bertely (2017) sobre educación en el Consejo Nacional de Fomento Educativo (CONAFE) y de Save the Children (2017) sobre protección de infancia, en temas como derechos, violencia, educación, salud y política pública, entre otros estudios.

\section{La infancia en números: estadísticas sobre la situación escolar de la infancia en México y Chiapas}

El estado mexicano de Chiapas presenta una composición diversa en lenguas, culturas, geografías, distribución de recursos, religiones y servicios educativos. Esto en algunos contextos se ha considerado una desventaja, sobre todo en modelos que buscan la homogenización y la estandarización de conductas. Aunque cuantificar la situación de la infancia no explica por completo las condiciones en las que viven niñas y niños, sí contribuye a conocer cómo está ubicado este sector en relación con otras poblaciones y al interior del sistema educativo mexicano.

Gran parte de las estadísticas agrupadas aquí corresponden a evaluaciones nacionales realizadas por el INEE, desde su creación en 2009 hasta su extinción en 2019. Las cifras reportadas por este instituto son de suma utilidad para desglosar algunos indicadores 
educativos no recogidos por otras instancias que reportan la estadística nacional, como el INEGI, el CONAPO, el Instituto Nacional de Salud Pública, la Organización Internacional del Trabajo, el Fondo de las Naciones Unidas para la Infancia (UNICEF), el Consejo Nacional para Prevenir la Discriminación, Save the Children y otras.

En México la educación es obligatoria, lo que se ha logrado en distintos momentos históricos (INEE, 2016:139): en 1917, primaria; en 1993, secundaria; en 2002, preescolar; ${ }^{4}$ para los niños de 3 años hacia 2008 (INEE, 2016:258), y en 2012 para la educación media superior. El 85\% de la educación preescolar se imparte con sostenimiento público, y no hay participación privada en servicio comunitario e indígena (INEE, 2019:36). En cuanto al periodo de escolarización diario, es de tres horas en promedio. Para el caso de escuelas preescolares: "según un estudio realizado por el INEE en 2011, la duración promedio de la jornada escolar es de 3.18 horas diarias; en los preescolares privados y comunitarios la duración se incrementa a 3.65 horas, mientras que en los generales e indígenas disminuye a menos de 3" (INEE, 2014:58).

La escuela en el nivel preescolar de manera institucional se concibe como un espacio para compensar diferencias y ayudar a que niñas y niños se equilibren en oportunidades: "el preescolar es la oportunidad para facilitar una plataforma común para todos los niños antes de iniciar la primaria, particularmente para aquellos que se encuentran en situaciones más vulnerables" (INEE, 2016:189). No obstante, tras más de quince años de haber sido considerada la educación preescolar como obligatoria, continúa un rezago en cuanto a la cobertura. El INEE reporta que 59.9\% de niñas y niños de 3 años, y $11.5 \%$ de 4 años, no están matriculados en preescolar, por lo que no se cumple la universalidad (2014:21). La asistencia es más discontinua en preescolar que en primaria y secundaria. Preescolar y educación media superior presentan una tasa neta de asistencia similar: en promedio asisten 7 de cada 10. De hecho, continúa siendo un reto para el sistema educativo mexicano la cobertura y la asistencia de estos dos niveles (INEE, 2018a y 2018b; INEE, 2019; Save the Children, 2017). El INEE atribuye la baja tasa de cobertura en preescolar a dos causas principales: la falta de oferta y la "renuencia" de padres y madres a enviar a sus hijos a la escuela (INEE, 2016:258). Esta renuencia en ocasiones es una posición política o cultural respecto a la crianza infantil, vinculada con el derecho de tener a la niña o al niño en casa y de enseñarle los saberes culturales-familiares, pues las prácticas de crianza presentan diferencias de una cultura a otra (Linares, 1991). Más adelante abordamos esta discusión respecto a la escolarización, puesto que se busca la inclusión en un sistema que no se conoce bien o, dicho de otra manera, se pretende la integración de la infancia en un sistema educativo formal sin tener una definición clara de los procesos educativos que se llevan a cabo al interior, por lo que se incluye a niñas y niños en un sistema que de antemano presenta diferencias y desigualdades, pues la calidad del servicio dependerá de la modalidad del preescolar y del sector geográfico donde esté ubicado (vid supra).

En un estudio ejecutado en 2013, se encontró que los inmuebles no fueron construidos expresamente para la atención con fines educativos de preescolar (INEE, 2014:55). En este sentido, ¿cómo es pensada la infancia en la agenda de la política pública? Se supondría que el contexto físico contribuye a logros de aprendizaje, lo que no se está cumpliendo debido a la falta de adaptación, a carencias o a la falta de pertinencia de ese contexto físico.

¿Cuántos niños y niñas están matriculados en educación inicial y preescolar? Tomando en cuenta la educación preescolar regular y la modalidad CONAFE, se observa que a las escuelas que agrupan mayor cantidad de niñas y niños se les denomina generales y mestizas. En el CONAFE, 85 de cada cien niños en preescolar asiste a la modalidad mestiza a nivel nacional, pero en Chiapas son 65, y 35 en modalidad indígena. Este dato es un indicador de que Chiapas es un estado que requiere atención especial debido a la presencia de indígenas, lo que supone revisar el desarrollo local propio de los pueblos donde habitan, los sistemas de convivencia, la ruralidad/urbanidad, la lengua específica y otros aspectos socioculturales (ver Tabla l). 
El CONAFE se plantea, como una estrategia gubernamental para llevar educación formal a zonas donde normalmente no llegan otras modalidades educativas, integrar educación inicial, preescolar, primaria y secundaria. A nivel nacional, en educación obligatoria - preescolar, primaria y secundariaatiende a 305958 personas, ascendiendo la población indígena a 46324 (Chiapas 20 228) y 256414 mestiza (Chiapas 39 322), y 3220 migrante. De la población indígena mexicana atendida por CONAFE, el estado de Chiapas atiende $43.6 \%$, y en el caso específico del nivel preescolar el porcentaje es aún más elevado, 46.7\% (CONAFE, 2018). En este punto llama la atención que Chiapas no atiende a población migrante, aunque constituye la frontera entre Norteamérica y la región mesoamericana, vía de tránsito terrestre de toda la migración de Centro y Sudamérica.

Recuérdese que el CONAFE es un servicio educativo soportado en términos operativos de atención directa a infantes por personal no profesional, que recibe algunas capacitaciones para atender educación multigrado en contextos rurales, indígenas y de poblaciones pequeñas. Esto quiere decir que un gran porcentaje de la población chiapaneca rural está siendo atendido bajo esas circunstancias. Aunque ha habido esfuerzos por comprender más la educación brindada por CONAFE y los procesos que ahí ocurren (Bertely, 2017), aún falta más comprensión sobre qué pasa con la interacción entre docentes jóvenes —denominados por CONAFE "líderes para la educación comunitaria” (LEC) - y niñas y niños, cuando los primeros no están profesionalizados, lo cual tiene implicaciones nodales si se carece de conocimientos y estrategias para organizar el aprendizaje en modalidades como el multigrado en contextos socioculturales específicos como los de comunidades indígenas, o se desconoce la estructura sociocultural en la que se expresa la diversidad y se invisibiliza la desigualdad.

Durante el ciclo escolar 2015-2016, los estudiantes que cursaban preescolares unitarios se ubicaban en Oaxaca (14.3\%), Tabasco (15.0\%), San Luis Potosí (14.6\%) y Chiapas (23.4\%), entidades que tenían menos centros preescolares con director: 18.9\% en Oaxaca y 15.7\% en Chiapas (INEE, 2017). Esta situación, por poner un ejemplo, contrastaba con la de la Ciudad de México, donde el $96.8 \%$ de preescolares tenían director.

Ahora bien, si nos centramos en los servicios educativos, se observa que los del tipo general están en mejores condiciones que los preescolares indígenas y comunitarios (INEE, 2018a; INEE, 2014), tanto en servicios educativos como en otros de la comunidad donde se ubican. En escuelas primarias y preescolares, y principalmente indígenas y rurales, el uso de computadoras aún es escaso (INEE, 2018a; INEE, 2014:57). Hay una suerte de urbanización de la educación, de manera que se priorizan las grandes poblaciones sobre las pequeñas y marginadas (INEE, 2019).

En Chiapas, en 2015 se reportaron 5217908 habitantes (INEGI, 2015). Según datos del INEGI (2010), el porcentaje nacional que hablaba una lengua indígena era de $6.7 \%$, mientras que en Chiapas era de $27.2 \%$, solo por debajo de Oaxaca (34.2\%) y Yucatán (30.3\%). La población total de niñas y niños entre 3 y 5 años (edad preescolar) era de 6647 805, de los cuales, estaban matriculados 4765841 (71.7\%); en Chiapas la cobertura era de $78.0 \%$. Esto demuestra que aún no se garantiza el derecho a acceso y cobertura educativa.

Esta separación en cuanto a servicios educativos, equidad y condiciones para el aprendizaje entre las escuelas rurales y las urbanas, estando las primeras claramente en desventaja, es una constante en el sistema educativo mexicano contemporáneo (INEE, 2014, 2015, 2016, 2017, 2018a, 2018b, 2019).

Proponemos referirnos a la educación rural a partir de tres grupos de escuelas: las generales en ámbitos rurales, las comunitarias — del CONAFE- y las indígenas campesinas. Las escuelas de los tres grupos comparten el hecho de que carecen de materiales y de infraestructura educativa, la formación docente es precaria y no se tiene un registro confiable de lo que en ellas se hace.

En cuanto a las escuelas comunitarias, además, tienen como característica que quien atiende a niñas y niños no es un profesional, a pesar de la complejidad de atender en una modalidad multigrado: una de cada dos 
escuelas de preescolar indígena es multigrado, y todos los centros comunitarios CONAFE, que representan un tercio de las escuelas multigrado del país, lo son (INEE, 2019:25). Del total de preescolares, 28.3\% es multigrado - en el caso de primaria es mayor, $43.2 \%$ (INEE, 2019:104)—. En educación multigrado se aplican dos modelos, el de la SEP y el de CONAFE (Ezpeleta, 2006:24).

De la población nacional, $10 \%$ es indígena y $6.5 \%$ hablante de una de las 68 lenguas originarias; "solamente $53 \%$ de los niños indígenas en edad de preescolar y primaria es atendido en una escuela bilingüe intercultural" (INEE, 2018:22). Esto indica la falta de pertinencia de contenidos y metodologías, que no están pensadas para este grupo. En cuando a la educación indígena, el INEE (2017; citando a INEE y UNICEF, 2016) comenta que, aunque niñas y niños tienen derecho a recibir educación en su propia lengua, ${ }^{5}$ en el caso de preescolar se observa que los docentes que hablan la lengua son $53.5 \%$. No obstante, aunque hablasen la lengua, esto no garantiza un proceso educativo efectivo, pues en muchas ocasiones no se imparte la educación en la propia lengua, por preferir la castellanización.

Respecto a los hablantes de lenguas indígenas (HLI): “a nivel nacional, de los 215278 alumnos HLI que asisten al nivel preescolar, el subsistema indígena atiende a 68\%; escuelas generales a 23\%; y servicios comunitarios a 9\%" (INEE, 2017:171). Esto es importante porque quiere decir que $32 \%$ de niñas y niños hablantes de una lengua asisten a escuelas generales, no pensadas para indígenas. Es decir, el derecho a recibir educación en la propia lengua y respetando el bagaje cultural, étnico e identitario no está garantizado, aunque idealmente se espera que la educación indígena se imparta por profesores competentes y que certifiquen su bilingüismo (INEE, 2016).

Las condiciones de infraestructura, equipamiento y acervo bibliográfico para zonas rurales, particularmente en escuelas indígenas y comunitarias, son precarias o no existen, ni siquiera servicios básicos, y se encuentran en desventaja con respecto a escuelas generales (INEE, 2019). Asimismo, aunque existan materiales en lengua indígena y sobre cultura indígena, están descontextualizados o no actualizados. También se produce una constante en capacitación y formación de docentes en el ámbito indígena: no están habilitados en contenidos ni en metodologías de enseñanza (INEE, 2017). Si a esto se suma la pertinencia del currículum, el cual está pensado con un sentido federalizado y principalmente para población urbana, la situación adquiere dimensiones más desconcertantes.

La evaluación educativa debe enmarcarse en la perspectiva de derechos (INEE, 2014:13). No se trata de una evaluación que haga notar las diferencias entre grupos per se, sino que los resultados son pretexto para la transformación y búsqueda de equidad. Para hacer posible lo que se cita en el artículo tercero de la Constitución Política de los Estados Unidos Mexicanos, el INEE (2019) identifica cinco implicaciones axiológicas y deontológicas de ese artículo: universalidad, equidad, logro — aprendizaje significativo-, suficiencia y calidad de la oferta, y mejora constante. Si se toman en consideración esas implicaciones por separado, se observará que la educación rural formal en general no ha logrado su cometido. Pero no solo eso, de algunos aspectos no existe suficiente información para establecer el estatus real de la problemática, por ejemplo en el caso del logro, la calidad de la oferta y la mejora constante.

Si se analiza el tema de la discapacidad, se observa que las Unidades de Servicios de Apoyo a la Educación Regular (USAER) no están disponibles para preescolares indígenas ni para los centros del CONAFE. Aunque ambas modalidades cuentan con "material" - programas, información- para atender ese tipo de situaciones (INEE, 2017), no se lleva a cabo una capacitación expresa para la atención, además de que se trata de ámbitos superespecializados. En este sentido, los LEC y los docentes indígenas carecen de competencia para la atención en niveles de diagnóstico, intervención, evaluación y canalización. Nuevamente, estas dos modalidades están fuera, a nivel estructural, de un tipo específico de atención que incluye el abordaje de aptitudes psicológicas, motrices, lingüísticas y sociales, entre otras. 
Excluyendo los tipos de servicios escolares indígenas y comunitarios, para Chiapas, en el ciclo escolar 2015-2016, se reportaban un total de 2452 escuelas preescolares regulares, de las cuales 267 tenían alumnos con discapacidad, y USAER atendía a 79 (29.6\%) de esas escuelas (INEE, 2017:96). A nivel nacional, "menos de la mitad de las escuelas regulares con estudiantes con discapacidad cuenta con la asesoría y el acompañamiento de las Unidades de Servicios de Apoyo a la Educación Regular (USAER): preescolar, 34.6\%" (INEE, 2019:83). Se desprende de lo anterior que el abordaje de la vulnerabilidad es complejo y ser indígena discapacitado sitúa al alumno o alumna en el fondo de la exclusión. ${ }^{6}$

Para el año 2017 el INEE incluye cifras sobre la discapacidad en preescolar. En educación básica no se han recabado datos de la mudez y la discapacidad múltiple. Si observamos en donde están ubicadas las niñas y niños según la discapacidad, en Escuela Regular (ER) o Centro de Atención Múltiple (CAM), se observan los siguientes porcentajes: ceguera, 624 (54.2 ER y 45.8 CAM); baja visión, 2930 (97.3 ER y 2.7 CAM); sordera, 1352 (79.2 ER y 20.8 CAM); hipoacusia, 1374 (82.1 ER y 17.9 CAM); motriz/física, 6900 (79.0 ER y 21.0 CAM); intelectual 10577 (64.5 ER y 35.5 CAM) (INEE, 2017:86, 88). No existen registros de la discapacidad en preescolares de educación inicial pues no está contemplada en estadísticas del formato estadístico 911 de la SEP, de donde se obtuvo esta información. A nivel nacional las escuelas preescolares que atienden estudiantes con discapacidad son 11.6\% (INEE, 2017:89). Los datos arriba enunciados dan cuenta de la necesidad formativa, y en general curricular y de acompañamiento, que requiere la atención en discapacidad. Solo la ceguera se atiende en porcentajes similares entre la ER y el CAM. Los estudiantes con otras discapacidades asisten en mayor porcentaje a las ER.

De nuevo destacan las limitaciones de servicios y de formas de operación de los centros, lo que afecta no solo al proceso educativo, sino a aspectos como la seguridad, la protección y la salud de niñas, niños y de docentes.
Posteriormente nos preguntamos qué tanto las actividades que se hacen en los preescolares se apegan al Programa de Educación Preescolar (PEP). El INEE hizo un estudio al respecto y llama la atención que hacia el año 2013 los preescolares generales dedicaban un $36 \%$ de su tiempo en congruencia con el PEC, 26\% comunitaria, 29\% indígena, y los preescolares privados $27 \%$. Es interesante observar que más de la mitad del tiempo en preescolares comunitarios (54\%) e indígenas (51\%) se destinaba a actividades no congruentes con el PEC. De hecho, a nivel nacional se dedicaba $35 \%$ a actividades no congruentes, y $32 \%$ a actividades congruentes con el PEP y con otros programas de la organización escolar (INEE, 2014:59). Precisamente, a fin de contribuir a acrecentar el conocimiento sobre el uso que se daba al tiempo, o mejor, sobre las actividades que se realizaban en el preescolar, diseñamos un instrumento denominado "línea de tiempo" para que docentes, LEC y cuidadoras indicaran lo que hacían durante una jornada escolar, del cual se obtuvo como resultado que se dedican a actividades de organización, lúdicas, de atención al centro y actividades formales de abordaje de contenidos curriculares.

Se podría pensar la escuela rural como un tipo específico de institución por las características del lugar donde se ubica (Vite, 2019). Por ejemplo, la ruralidad, que en sí misma expresa ciertas condiciones como población escasa, marginalidad de servicios básicos o dedicación productiva predominantemente primaria - agricultura, ganadería, pesca, foresteríaimplica ciertos condicionamientos para las acciones que se ejecutan en áreas rurales, lo que representa retos especiales para el sistema educativo mexicano (Fuenlabrada y Weiss, 2006).

En el año 2002 se estableció la obligatoriedad del preescolar (INEE, 2015). De acuerdo con el INEE, el sistema educativo mexicano a partir de la reforma de 2013 incorpora el concepto de calidad, y se atribuye la educación como un derecho humano. Esta obligatoriedad a la escolarización temprana no integra la diversidad de crianzas (Núñez, 2018) y no 
solo tiene que ver con la pérdida de prácticas culturales tradicionales:

\section{[...] la institucionalización de la educación inicial lleva consigo algunas características que se cuestionan desde esta visión de derecho infantil y desde muchos de los principios de los mismos campos disciplinares que dieron origen a la atención educativa temprana: la universalización de la formación, la desvinculación afectiva y cultural de la socialización temprana y la colocación de las prioridades educativas escolares por encima de las familiares (Ayora, 2018:12).}

Políticas de esta envergadura afectan de manera profunda en los entornos rurales en general, y en los indígenas en particular, al no integrar los contextos de las familias, y tampoco logran una cobertura efectiva y la tan anunciada calidad; sigue siendo el discurso vacío de la promesa educativa en México, es decir, la continuidad de la colonialidad del poder (Quijano, 2000).

\section{Docentes de preescolar}

Según un informe del INEE del año 2015, hay 93 mujeres por 7 hombres por cada 100 docentes. Además, "La participación femenina no es uniforme entre los tipos de servicio. En educación preescolar, independientemente del sostenimiento, 24 de cada 25 docentes en escuelas generales son mujeres; esta proporción disminuye en los preescolares indígenas (87.4\%) y en los cursos comunitarios (72.6\%)" (INEE, 2015:31-32). Además, los docentes de preescolar son relativamente más jóvenes que los de primaria y secundaria. En este mismo sentido, al ser la población más joven, es la que tardará más en entrar al proceso de jubilación respecto a quienes trabajan en otros niveles.

De acuerdo con el informe del INEE (2019:65), cuatro de cada diez docentes reportaron que promovían el trabajo en equipo en preescolar. La práctica de acompañamiento pedagógico para educadores no es generalizada, las escuelas indígenas y las privadas fueron las que menos acompañamiento tuvieron (INEE,
2019:80). Solo 56\% de los educadores de preescolar reportó que contaba con el plan y programa de estudio (INEE, 2019:18). "Las acciones pedagógicas más recurrentes son: en preescolar, orientar a los padres para que apoyen a sus hijos en las tareas (94.9\%)" (INEE, 2019:82). De los libros de texto gratuito, tres de cada diez docentes de preescolar de la opción comunitaria, que tenían libro propio del modelo educativo, reportaron que contaban con todos los libros (INEE, 2019:18).

UNICEF reporta que, aunque hay avances en servicios públicos, en política pública, en normatividad y en temas educativos, estos avances están más dirigidos a las ciudades, mientras quedan carentes de esta protección y de estos derechos niñas y niños que habitan en sectores rurales y en las periferias de las ciudades (UNICEF, 2013). Asimismo, propone la necesidad de llevar a cabo un trabajo interinstitucional coordinado, ya que muchos factores que afectan a la infancia tienen que ver también con problemas estructurales más amplios como la pobreza y la marginación, que derivan en desigualdad social (UNICEF, 2013). De acuerdo con el estudio de Núñez, Alba y Molinari (2016), en los centros de atención de infancias en San Cristóbal de Las Casas, Chiapas —quizá la ciudad que más congregación tiene de población infantil indígena-, los modelos de atención están centrados en el cuidado y la asistencia. Por tanto, la participación de la niñez está anulada puesto que se retoman modelos adultocéntricos que se focalizan en la niñez y que están basados en teorías de la democracia que no se dirigen expresamente al sentir y pensar de niñas y niños. Véase el caso de los diseños y las construcciones arquitectónicas que no son los adecuados para la infancia ni para los entornos en donde viven (vid supra, resultados). En Chiapas, en los años 2010, 2012, 2014 y 2016, de cada diez personas siete eran pobres, nueve tenían al menos una carencia social (90.9\%), cuatro tres carencias sociales (40.6\%), tres presentaban rezago educativo (29.0\%), y tres se encontraban en situación de pobreza extrema (28.1\%) (CONEVAL, 2016). 


\section{Inclusión y marginación en educación preescolar en México}

Uno de los sentidos axiológicos de la educación es que ésta sea en beneficio de personas y de la sociedad, y por tanto que llegue a todas y todos. Sin embargo, tal pretensión no se está logrando en México pues la marginación es alarmante tanto entre estudiantes como en escuelas. Advertimos que Chiapas es de los estados con marginación extrema en alumnos de preescolar (ver Tabla 2).

A partir de los datos recopilados en la Tabla 2 puede analizarse que los servicios educativos indígena y comunitario no están disponibles en todos los estados de la República: no hay servicios educativos comunitarios en la Ciudad de México, ni servicios educativos para indígenas en Aguascalientes, Baja California Sur, Coahuila, Colima, Ciudad de México, Nuevo León, Tamaulipas y Zacatecas, por lo que las niñas y niños migrantes o desplazados a esos estados no reciben atención especial de estos tipos. En general, el sureste es donde más alta marginación se observa. A fin de plasmar gráficamente el comportamiento de la marginación en esta región nos dimos a la tarea de hacer un análisis y presentarlo en un mapa de la República mexicana (ver Figura 1). Se agruparon los porcentajes para los tres tipos de servicios - general, indígena y comunitario - en tres categorías: grupo l (gris oscuro), cuando más de 50\% de marginación alta y muy alta en los tres servicios; grupo 2 (gris medio), entre 20 y menos de 50\% en alguno de los grupos, y grupo 3 (gris claro), menos de $20 \%$ para al menos un servicio.

Como hacemos notar, todo el país presenta porcentajes de alta y muy alta marginación, siendo nuevamente los servicios educativos indígena y comunitario los que mayor porcentaje presentan, llegando incluso a detectarse $100 \%$ de alta y muy alta marginación en alumnos y escuelas en el estado de Tlaxcala. A fin de hacer notar la desigualdad en el país, obsérvese cómo la marginación depende de donde están ubicados estudiantes y escuelas. El grupo uno (color rojo) es el que presenta datos más alarmantes e incluye los estados de Chiapas, Campeche, Guerrero, Veracruz,
Puebla, Michoacán, Morelos y Tlaxcala (ver Figura 1).

Después de Guerrero, Chiapas es la entidad que presenta el índice más elevado de marginación en cuestión de educación preescolar. Frente a estas cifras, se presenta una tendencia compensatoria en dos rubros sustantivos, la salud y la educación, que, como sostiene Ayora:

\begin{abstract}
Esta tendencia de atención compensatoria de salud y educativa se agudiza con los parámetros neoliberales de los sistemas educativos, que se caracterizan por asumir en el discurso la diversidad cultural y educativa, pero en los hechos y en las propuestas mantienen mecanismos y parámetros de universalización del desarrollo infantil, de la crianza y de la socialización, justificados por la supuesta inclusión para un proceso exitoso de las niñas y los niños en la escolarización posterior (Ayora, 2019:6).
\end{abstract}

Estos mecanismos de universalización se encuentran aún vigentes, pero encubiertos en políticas positivas para la atención a poblaciones "deficitarias". Lo anterior evidencia la continuidad de la desvalorización de la población indígena y rural en México, y su exclusión con el discurso cínico de la "calidad" y la "inclusión".

\section{Metodología del estudio}

La investigación se desarrolló en la zona Costa de Chiapas, México, en los municipios de Arriaga, Tonalá, Pijijiapan y Mapastepec. Esta zona es una de las más vulnerables del estado. Usamos un enfoque mixto de investigación integrando herramientas cuantitativas y cualitativas para la recolección y análisis de información, para describir y para obtener una comprensión del centro escolar desde la visión de los sujetos. Los instrumentos de investigación que se elaboraron para esta investigación fueron tres de carácter cuantitativo: lista de chequeo, cuestionario, toma fotográfica; y dos cualitativos: entrevista y línea de tiempo. En este artículo se revisarán los resultados de la lista de chequeo. La información se obtuvo preguntando a un informante clave del centro que conociera todos 
los aspectos de la institución indicando si el elemento se encontraba presente (sí, parcialmente o no). La respuesta "parcialmente" indica que hay cierto grado de existencia del aspecto, pero no está completo. Por ejemplo, si se pregunta si hay barda perimetral y solamente una parte del centro cuenta con ella, se anotaría "parcialmente". Se presenta como anexo la lista de chequeo completa. Las áreas exploradas fueron:

1. Prácticas de atención y de educación: elementos curriculares y prácticas de atención específicas.

2. Aspectos legales: regulaciones para ordenar y establecer condiciones de derechos, buen funcionamiento y protección de la infancia, coordinación de manera normativa de las interacciones y el funcionamiento de los centros, los actores y los usuarios.

3. Formación docente: habilitación docente en la atención y cuidado de la infancia

4. Infraestructura, equipamiento y financiamiento: aspectos físicos de las escuelas imbricados en el proceso de atención infantil: objetos, muebles, lugar y material.

A los docentes, cuidadores, LEC y autoridades de las instituciones se les solicitó que expresaran abiertamente su autorización para participar. Se integraron al estudio los siguientes tipos de centros que atienden a infancia: nueve preescolares generales, veintinueve centros educativos comunitarios (CONAFE) y un Centro de Desarrollo Infantil.

\section{Resultados}

Una escuela preescolar participante estaba tipificada como general, pero consideramos que debería estar clasificada como indígena, pues aunque estaba ubicada en una zona mayormente mestiza - la zona Costa - la población era indígena, desplazada, hablante de tsotsil y conservaba costumbres propias como la vestimenta. Niñas y niñas se matriculaban para cubrir el requisito formal de obligatoriedad, pero no asistían regularmente. Esta situación refleja otras circunstancias de la educación rural e indígena: la lengua y la adscripción formal de la institución al tipo de modalidad de que se trate. En la entrevista al docente del preescolar citado, este comentó que no asistían muchos niños. El entrevistador recorrió la comunidad en busca de un lugar para comer y en una tienda de abarrotes la tendera le comentó que podría ofrecer ese servicio. El servicio de comida se proveyó dentro de la casa. Al pasar al patio advirtió la presencia de niños y niñas de distintas edades, algunos evidentemente en edad preescolar, que en horario de clases estaban en casa, conviviendo con sus madres. Esto hace visible la relación que se establece entre la primera infancia y la familia.

A continuación se presentan resultados de la lista de chequeo sobre las cuatro áreas. Para consultar las subáreas e indicadores de cada área, véase la Tabla 3 , donde se ratifica la tendencia mostrada por los datos anteriormente presentados: que las condiciones educativas en contextos escolares rurales son deficientes en cuanto a la atención y la práctica con infantes, la formación docente, aspectos legales e infraestructura y equipamiento. También, nótese que hay diversidad de condiciones en cada centro; por tanto, cuando se habla de educación preescolar en realidad se habla de "educaciones preescolares", es decir, es necesario mencionar la particularidad (ver Tabla 3). El CENDI obtuvo en general mejores porcentajes que el resto de instituciones. Para mostrar visualmente esas diferencias, en la Figura 2 se expone la desigualdad en un tema tan básico como los servicios sanitarios (ver Figura 2).

En el preescolar unitario los sanitarios se ubicaban en una construcción abandonada, con hojarasca, y se observaron algunas heces. De hecho, ese centro escolar no contaba con agua corriente. En el CENDI, las condiciones eran distintas; contaba con baños, mingitorios y lavamanos a la altura de niñas y niños, con decoración, con piso firme de loseta y con agua corriente. En el sanitario del CONAFE se observó solo una taza para persona adulta, sin depósito para el agua. Esta diversidad de condiciones en cuanto a deterioro o inexistencia de servicios generales y para la atención infantil se observó en prácticamente todos los centros evaluados. 


\section{Discusión}

En la escuela, como espacio público de relación, se llevan a cabo, de acuerdo con Hecht (2013), yuxtaposiciones, tensiones y disputas entre los saberes y prácticas familiares, y en ella influyen relaciones de parentesco y simbolismos culturales. En el caso de las culturas rurales e indígenas, por sus configuraciones lingüísticas y cosmogónicas los encuentros entre el bagaje cultural y el propuesto por la escuela se contraponen, e incluso las visiones que se ofrecen juegan a favor intencional de lo propuesto en la escuela, como una forma de legitimar conocimientos, procedimientos y epistemologías.

En ese sentido, en su reflexión sobre la escolaridady el uso de la lengua en ella, Hecht concluye lo siguiente: "La escuela se presenta ambigua y simultáneamente como un agente habilitante y limitante" (2013:417). Se entiende que definitivamente la escuela, por su estructura curricular y su intencionalidad formativa, puede deparar beneficios para el desarrollo humano; sin embargo, su intencionalidad de crear ciudadanías específicas es restrictiva y focalizada en una sola perspectiva excluyente, pues aunque sea de interés atender la diversidad y se integre discursivamente, no logra, en el campo operativo, resultar en una ejecución. Aun así, los debates en torno a la educación en la diversidad e interculturalidad continúan no solo en educación básica, sino en la universitaria (Jiménez, 2011). La apropiación cultural y cómo se usa el conocimiento cultural para desarrollar habilidades sociocognitivas pueden variar de una cultura a otra (Callaghan et al., 2011).

Los instructores y docentes deben tener conocimientos y habilidades, es decir, competencias que les permitan ser promotores del desarrollo humano. Cuando se trata de educación rural e indígena, el hecho de que tengan competencia en hablar la lengua y en vinculación comunitaria permite atender mejor las necesidades que el contexto sociocultural requiere (Gómez, 2010). La educación implicaría la consideración de la cultura en el desarrollo y cómo se construye el aprendizaje de manera conjunta, en comunidad (Rogoff, 1994, 2003).
El debate sobre la educación escolarizada formal, la coeducación con la comunidad o la etnoeducación sigue activo a nivel internacional (Huertas, Esmeral y Sánchez, 2014). En ocasiones las docentes mismas, aún en activo, no conocen las implicaciones de su práctica. Por ejemplo, en una investigación con docentes de preescolar se observó que conocen en términos generales la evaluación, pero la utilizan de manera personal, más que para facilitar el proceso de aprendizaje de niñas y niños (Sañudo y Sañudo, 2014).

La evaluación del nivel preescolar es compleja dado que implica valorar condiciones físicas de los locales donde se imparte la educación, así como los materiales, la habilitación docente, los modelos de enseñanza y aprendizaje que están detrás, el financiamiento, los actores y sus formas de participación, así como la caracterización del tipo de servicio de que se trate (Pérez, 2010).

El programa educativo de preescolar 201l, en su concepción, es interesante y vale la pena referenciarlo:

La naturaleza de los procesos de desarrollo y aprendizaje, así como la diversidad social y cultural del país, hace sumamente difícil establecer una secuencia detallada de situaciones didácticas o tópicos de enseñanza, por lo cual el programa no presenta una secuencia de actividades o situaciones que deban realizarse sucesivamente con las niñas y los niños (SEP, 2015).

En realidad, ese carácter abierto de las secuencias didácticas es tan atractivo como impreciso, en el sentido de que idealmente se debería tener la habilidad, como docente o LEC, para improvisar y adaptar contenidos, tiempos y actividades de desarrollo psicológico a fin de propiciar las condiciones idóneas. Pero, pragmáticamente, tales procesos no se llevan a cabo de manera efectiva.

ElConsejo Nacional para Prevenir la Discriminación (CONAPRED) plantea las siguientes preguntas:

[...] icuánto de lo que realizan los gobiernos federal, estatales y municipales está discriminando a las 
y los menores de edad?, ¿cómo les niega este trato diferenciado el ejercicio de sus derechos por su condición de edad?, ipor qué la niñez mexicana carece de mecanismos formales de participación que recojan sus opiniones en torno a la vida nacional? (CONAPRED y UNICEF, 2011:12).

Estas preguntas conducen a pensar los modos en que se concibe a las infancias. Más de ocho de cada diez niñas y niños, a nivel nacional, mencionaron que la casa es el lugar más importante (95\%) y la escuela el segundo (CONAPRED y UNICEF, 2011:34). No obstante, sobre las posibles carencias de la escuela llama la atención que en la Encuesta Nacional sobre la Discriminación en México 2010 los niños mencionaron que obedecen más a los maestros que a sus padres y a otras figuras. Esto habla de la disciplina en la escuela, pero también del respeto que sienten por ella (CONAPRED y UNICEF, 2011:40).

Si bien las sociedades industrializadas y urbanizadas han creado modelos de educación formal dirigidos principalmente por instrucciones verbales, también hay sociedades que usan menos instrucción verbal y más otras formas de aprendizaje (Callaghan et al., 2011). No es que se niegue la educación formal ni sus posibilidades para el desarrollo, más bien se pretende que esta sirva para potenciar el aprendizaje y la vida infantil, integrando, subsumiendo, criticando y reflexionando los saberes locales. El salón es una oportunidad de intercambio entre estudiantes y profesores, en una participación en contextos comunitarios (Rogoff, Matusov y White, 1996), pero claro está que lo que los docentes conocen del desarrollo infantil contribuye a su práctica, es decir, dependiendo de lo que conozcan del desarrollo será su forma de dirigir la práctica (Daniels y Shumow, 2003).

\section{Conclusión}

Los centros preescolares de la zona Costa de Chiapas presentan condiciones de aprendizaje insuficientes, inexistentes o no adecuadas. El aspecto en el que más ayuda se necesita es en las condiciones de atención de la discapacidad.

Sobre la obligatoriedad de la escolaridad en la infancia, Ayora cuestiona precisamente la linealidad del tipo de educación que provee la escuela, pero hay que considerar, como ella menciona, que "la mirada compleja de lo epistémico es fundamental para dar lugar a reconsiderar otras educaciones y otras formas de estar en el mundo, más allá de las dominantes y con procesos reflexivos y críticos". Y comenta la necesidad de "una interculturalización crítica de la escuela" (Ayora, 2018:2), es decir, de un modelo reflexivo de diálogo entre actores diversos, los formales -institucionales - y los informales —usuarios, padres y madres; comunidad en general-.

El concepto de obligatoriedad establecido por el Estado conlleva también la responsabilidad pública del servicio y su calidad; y atendiendo a otros preceptos de la Constitución, implicaría el respeto y la integración de aspectos culturales. En nuestro estudio sobre centros preescolares de la zona Costa encontramos que hay deficiencias y que estos presentan características muy desiguales. Un asunto importante es que la escuela no constituya una mordaza de los imaginarios y construcciones simbólicas socioculturales desarrollados en casa y en la comunidad.

La promesa política y discursiva del logro de calidad universal para la primera infancia sigue siendo una deuda histórica, y mientras no se establezcan condiciones similares para el aprendizaje y el desarrollo, entendiendo por similaridad la igualdad de oportunidades, mientras este proceso no se haga de manera integrativo con los saberes, conocimientos y prácticas locales, no se estará en posibilidad de decir que se ha logrado la inclusión y la equidad en la educación.

\section{Notas}

${ }^{1}$ Ver: Rogoff (1994 y 2003).

${ }^{2}$ Ver: Alanen (2012).

${ }^{3}$ Otra fuente del INEE (2017:14) refiere la obligatoriedad en el año 1934 y para preescolar marca 2003. 
${ }^{4}$ Aunque INEE precisa, "en preescolar la obligatoriedad se dio de forma gradual: en el ciclo 2004-2005 para tercer grado; en el 2005-2006 para segundo, y en el 2008-2009 para primero" (2017: 14); en otro momento se indica que la obligatoriedad fue en 2002 (INEE, 2018: 44). Ahora, son obligatorios los tres grados de preescolar (3 a 5 años).

${ }^{5}$ La lengua indígena como lengua materna, y segunda lengua, y el español como segunda lengua ya se introdujeron en el currículum 2017, lo que se observa como un reconocimiento y revalorización de la lengua (INEE, 2018:35). En el año 2018 se expidió la Ley del Instituto Nacional de los Pueblos Indígenas, que en su fracción XLI menciona respecto a su intervención en educación formal: "Coordinar con las instancias correspondientes, el reconocimiento y la implementación de la educación indígena en todos sus tipos y niveles, así como participar en la elaboración de los planes y programas de estudio, y materiales didácticos específicos dirigidos a los pueblos indígenas, con la finalidad de fortalecer las culturas, historias, identidades, instituciones y formas de organización de dichos pueblos"; y en la fracción XLII menciona: "Crear los espacios necesarios y dignos para la atención integral e intercultural de los niños, niñas y jóvenes indígenas y afromexicanos, tanto en sus regiones como fuera de ellas".

${ }^{6}$ Esto en referencia a la atención en educación formal, porque sería necesario estudiar cómo se atiende la saludenfermedad mental en determinadas comunidades indígenas.

\section{Referencias}

Alanen, Leena (2012). "Disciplinarity, Interdisciplinarity and Childhood Studies". En Childhood, 19(4), 419-422. Ayora, Gialuanna (2018). Resistencias epistémicas en Sahkaba', Yucatán. Crianza, socialización y participación en torno a la niñez maya en la educación inicial. Tesis doctoral. México: Instituto de Investigaciones en Educación-Universidad Veracruzana.

Ayora, Gialuanna y Patricia Medina (2016) "Reflexiones metodológicas: interculturalidad, horizontalidad, co/labor epistémica y de/colonialidad. Taller de literacidad en educación inicial con niñez mayayucateca". En Revista de Derechos Humanos y Estudios Sociales, 8(16), 49-78.

Bertely, María (2017). Análisis y propuestas para el fortalecimiento del Programa de Educación Inicial del CONAFE, una mirada antropológica. México: SEP/UNICEF/ CONAFE.

Callaghan, Tara et al. (2011). "Early Social Cognition in Three Cultural Contexts". En Monographs of the Society for Research in Child Development, 76(2), 7-128.

CONAFE (2018). "Informe Estadístico InstitucionalCierre del ciclo escolar 2018". México: CONAFE. Disponible en: https://cnfsiiinafe.conafe.gob.mx/ CONAFEEnCifras/Cifras/MostrarCifras/ (consultado el 15 de mayo de 2019).

CONAPRED y UNICEF (2011). Encuesta nacional sobre la discriminación en México. Enadis 2010. Resultados sobre niñas, niños y adolescentes. México: CONAPRED/UNICEF.

CONEVAL (2016). "Porcentaje, número de personas y carencias promedio por indicador de pobreza. Chiapas 2010-2016". México: CONEVAL. Disponible en: https:/www.coneval.org.mx/coordinacion/entidades/ Chiapas/PublishingImages/Chiapas_Cuadrol.JPG (consultado el 1 de mayo de 2019).

Daniels, Denise y Lee Shumow (2003). "Child Development and Classroom Teaching: A Review of the Literature and Implications for Educating Teachers". En Journal of Applied Developmental Psychology, 23(5), 495-526.

Ezpeleta, Justa (2006). "La gestión pedagógica de las escuelas multigrado". En Irma Fuenlabrada y Eduardo Weiss (coords.), Prácticas escolares y docentes en las escuelas primarias multigrado. México: Consejo Nacional de Fomento Educativo, pp. 23-48.

Fuenlabrada, Irma y Eduardo Weiss (coords.) (2006). Prácticas escolares y docentes en las escuelas primarias multigrado. México: Consejo Nacional de Fomento Educativo.

Gómez Zermeño, Marcela G. (2010). "Competencias interculturales en instructores comunitarios que brindan servicio a la población indígena del estado de Chiapas". En Revista Electrónica de Investigación Educativa, 
12(1). Disponible en: http://redie.uabc.mx/voll2nol/ contenido-gomezzermeno.html (consultado el 19 de mayo de 2019).

Hecht, Ana Carolina (2013). "Niñez, escolarización y lengua indígena. Una mirada antropológica sobre la diversidad lingüística en la escuela". En Revista de Educação Publica, 49(2), 405-419.

Hirokazu, Yoshikawa et al. (2007). Early Childhood Education in Mexico: Expansion, Quality Improvement and Curricular Reform. Innocenti Working Paper núm. 200703. Florencia: UNICEF Innocenti Research Centre.

Huertas, Omar, Simón José Esmeral e Iván Manuel Sánchez (2014). "La educación en comunidades indígenas; Frente a su proyecto de vida en un mundo globalizado". En Revista Logos Ciencia e Tecnología, 5(2), 232-243.

INEE (2014). El derecho a una educación de calidad. Informe 2014. México: INEE.

INEE (2015). Los docentes en México. Informe 2015. México: INEE.

INEE (2016). La educación obligatoria en México. Informe 2016. México: INEE.

INEE (2017). La educación obligatoria en México. Informe 2017. México: INEE.

INEE (2018a). La educación obligatoria en México. Informe 2018. México: INEE.

INEE (2018b). Principales cifras. Educación básica y media superior. Inicio del ciclo escolar 2016-2017. México: INEE.

INEE (2019). La educación obligatoria en México. Informe 2019. México: INEE.

INEGI (2010). Censo de Población y Vivienda 2010. México: INEGI.

INEGI (2015). Encuesta Intercensal 2015. México: INEGI.

James, Adrian L. (2010). "Competition or Integration? The Next Step in Childhood Studies?" En Childhood, 17(4), 485-499.

Jiménez, Yolanda (2011). "Los 'enunciados' de la escuela intercultural en el ámbito de los pueblos indígenas de México". En Desacatos, 35, 149-162.

Linares, María Eugenia (1991). "Pautas y prácticas de crianza en México. Recopilación de información de fuentes secundarias". En Revista Latinoamericana de Estudios Educativos, 21(3), 113-137.
Meisels, Samuel J. Jack P. y Shonkoff (2000). "Early Childhood Intervention: A Continuing Evolution". En Jack P. Shonkoff y Samuel J. Meisels (eds.), Handbook of Early Intervention. Nueva York: Cambridge University Press, pp. 3-34.

Núñez Patiño, Kathia (2018). Construcción identitaria de niños y niñas en dos comunidades indígenas, desde sus discursos y prácticas de tres ámbitos de sentido: la comunidad, la casa y la escuela. Tesis doctoral. México: Instituto de Investigaciones en Educación, Universidad Veracruzana.

Núñez Patiño, Kathia, Cecilia Alba y Claudia Molinari (2016). "Infancias indígenas. Los centros de atención a la niñez en Chiapas y el reto de la educación intercultural frente a la diversidad". En LiminaR. Estudios Sociales y Humanísticos, 14(1), 106-120.

Pérez Martínez, María Guadalupe (coord.) (2010). La educación preescolar en México. Condiciones para la enseñanza y el aprendizaje. México: Instituto Nacional para la Evaluación de la Educación.

Quijano, Aníbal (2000). "Colonialidad del poder, eurocentrismo y América Latina”. En Edgardo Lander (comp.), La colonialidad del saber: eurocentrismo y ciencias sociales. Perspectivas Latinoamérica. Buenos Aires: CLACSO, pp. 201-246.

Rogoff, Barbara (1994). "Developing Understanding of the Idea of Communities". En Mind Culture and Society, 1(4), 209-229.

Rogoff, Barbara (2003). The Cultural Nature of Human Development. Nueva York: Oxford University Press.

Rogoff, Barbara, Eugene Matusov y Cynthia White (1996). "Models of Teaching and Learning: Participation in a Community of Learners". En David R. Olson y Nancy Torrance (eds.), The Handbook of Education and Human Development: New Models of Learning, Teaching and Schooling. Oxford, Gran Bretaña: Blackwell, pp. XII, 804.

Sañudo, Lya y María Isabel Sañudo (2014). "Las concepciones explícitas sobre evaluación en la práctica docente en educación preescolar en Jalisco, México". En Revista Iberoamericana de Evaluación Educativa, 7(1), 31-42.

Save the Children (2017). Los peligros para la niñez. Indicadores para México. México: Save the Children. 
SEP (Secretaría de Educación Pública) (2015). UNICEF (2013). Los derechos de la infanciay la adolescencia en "Educación preescolar". México: Gobierno de México. Disponible en: https://www.gob.mx/sep/es/acciones-yprogramas/educacion-preescolar (consultado el 19 de mayo de 2019).

Tisdall, E. Kay M. y Samantha Punch (2012). "Not so 'New'? Looking Critically at Childhood Studies". En Children's Geographies, 10(3), 249-264.

Chiapas. México: UNICEF.

UNICEF (2018). La agenda de la infancia y la adolescencia 20192024. México: UNICEF.

Vite, Alma Elizabeth (2019). "La práctica educativa de profesores en escuelas rurales. La homogeneización imposible". En Revista Latinoamericana de Estudios Educativos, 49(1), 185-208. 
Figura 1. Muy alta y alta marginación de alumnos y escuelas preescolares

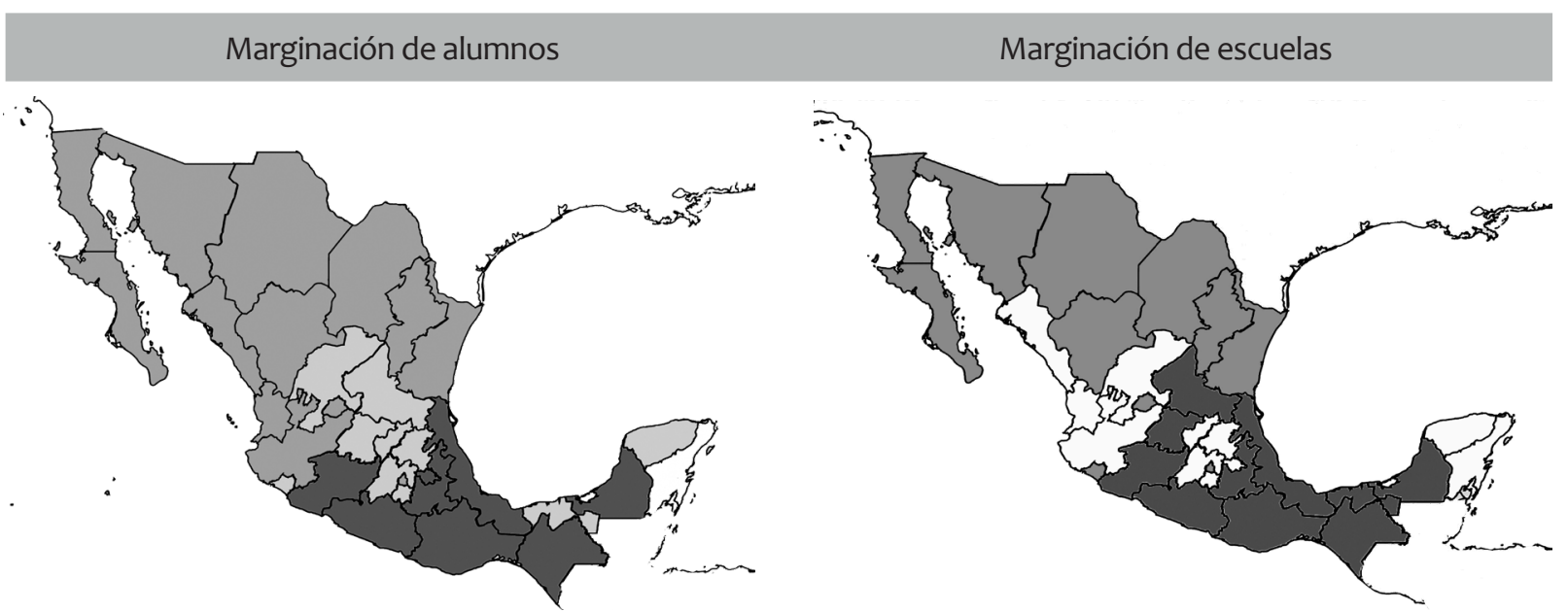

Fuente: elaboración propia usando mapchart.net, con datos del INEE (2018b). Principales cifras. Educación básica y media superior. Inicio del ciclo escolar 2016-2017.

Figura 2. Instalaciones de sanitarios en tres centros preescolares de la zona costa
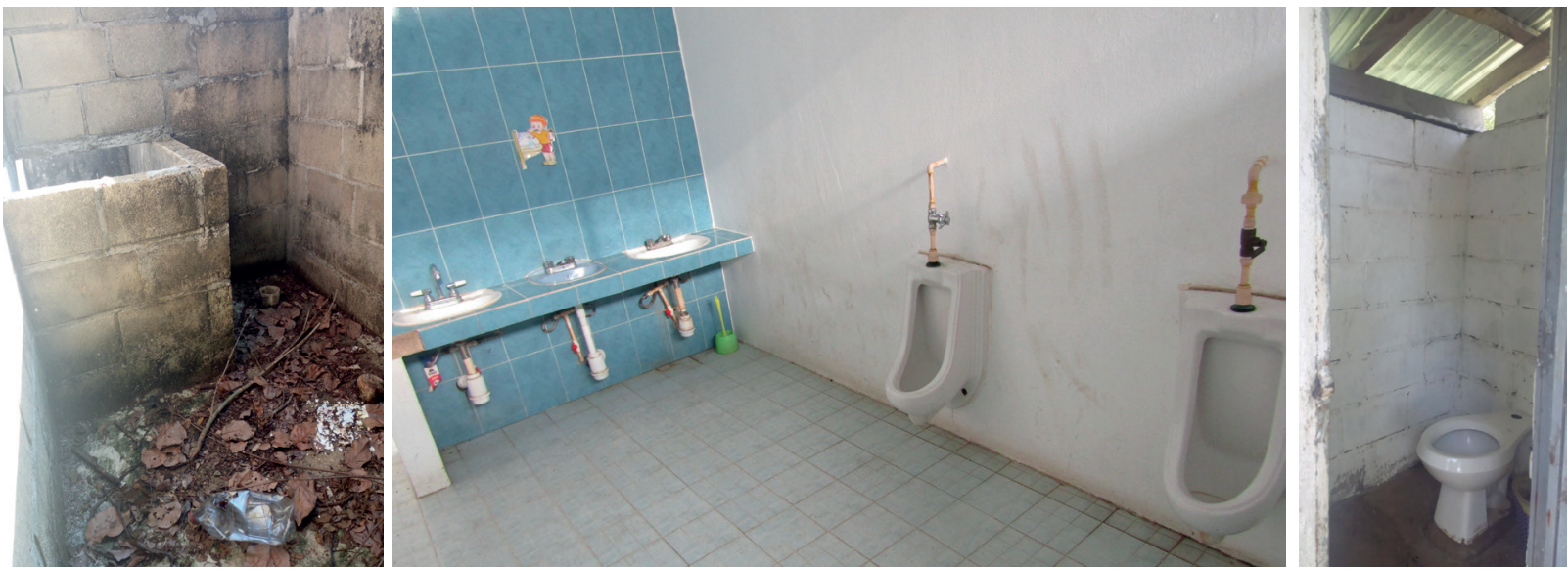

Fuente: archivo de investigación. Sanitarios de tres sitios distintos: un preescolar unitario (P6), un CENDI (CE52) y un preescolar de CONAFE (Cl4). 
Tabla 1. La educación inicial y básica preescolar en México y Chiapas 2018

\begin{tabular}{|c|c|c|c|c|c|}
\hline \multirow{9}{*}{$\begin{array}{l}\text { Educación básica } \\
\text { preescolar }\end{array}$} & & Tipo de servicio & Alumnos & $\begin{array}{l}\text { Escuelas/ } \\
\text { planteles }\end{array}$ & Docentes \\
\hline & \multirow{4}{*}{ Nacional } & Total preescolar & 4931986 & 88939 & 234635 \\
\hline & & $\begin{array}{c}\text { General (incluye } \\
\text { CENDI) }\end{array}$ & 4343899 & 60864 & 196121 \\
\hline & & Indígena & 423344 & 9838 & 19031 \\
\hline & & Comunitario & 164743 & 18237 & 19483 \\
\hline & \multirow{4}{*}{ Chiapas } & Total preescolar & 299950 & 7207 & 13429 \\
\hline & & General & 180811 & 2759 & 7349 \\
\hline & & Indígena & 92012 & 1983 & 3282 \\
\hline & & Comunitario & 27127 & 2465 & 2798 \\
\hline \multirow{9}{*}{ CONAFE } & & Modalidad & $\begin{array}{l}\text { Educación } \\
\text { preescolar }\end{array}$ & $\begin{array}{l}\text { Servicios } \\
\text { educativos }\end{array}$ & $\begin{array}{l}\text { Figuras } \\
\text { educativas }\end{array}$ \\
\hline & \multirow{4}{*}{ Nacional } & Total preescolar & 163303 & 18430 & 19392 \\
\hline & & Mestizo & 140385 & 16098 & 16661 \\
\hline & & Indígena & 20426 & 2158 & 2377 \\
\hline & & Migrante & 2098 & 132 & 310 \\
\hline & \multirow{4}{*}{ Chiapas } & Total preescolar & 26879 & 2409 & 3058 \\
\hline & & Mestizo & 17323 & 1555 & 1984 \\
\hline & & Indígena & 9556 & 854 & 1074 \\
\hline & & Migrante & 0 & 0 & 0 \\
\hline
\end{tabular}

Fuente: elaboración propia con base en datos del "Informe Estadístico Institucional-Cierre del ciclo escolar" (CONAFE, 2018) y del documento "Principales cifras. Educación básica y media superior. Inicio del ciclo escolar 2016-2017" (INEE, 2018b). Los datos de "Educación básica preescolar" incluyen los datos del CONAFE, solo que en este apartado de la tabla se describe a detalle. 
Tabla 2. Grado de marginación muy alto y alto

\begin{tabular}{|c|c|c|c|c|c|c|}
\hline \multirow{3}{*}{ Estado } & \multicolumn{6}{|c|}{ Marginación según tipo de servicio educativo (porcentaje) } \\
\hline & \multicolumn{2}{|c|}{ General } & \multicolumn{2}{|c|}{ Indígena } & \multicolumn{2}{|c|}{ Comunitario } \\
\hline & Alumnos & Escuela & Alumnos & Escuela & Alumnos & Escuela \\
\hline Aguascalientes & 7.7 & 7.8 & - & - & 29.8 & 30.6 \\
\hline Baja California & 10.9 & 10.6 & 68.5 & 72.5 & 41.6 & 41.2 \\
\hline Baja California Sur & 10.9 & 9 & - & - & 68.1 & 52.4 \\
\hline Campeche & 50.7 & 55.7 & 93.4 & $93 \cdot 3$ & 89.1 & 85.6 \\
\hline Coahuila & 6.6 & 6.9 & - & - & 44.6 & 43.3 \\
\hline Colima & 21.9 & 19.9 & - & - & 65.4 & 63.8 \\
\hline Chiapas & 73.4 & 80.7 & 96.9 & 96.2 & 93.6 & 91.5 \\
\hline Chihuahua & 7 & 11.1 & 83.8 & 86.3 & 59.5 & 62.1 \\
\hline Ciudad de México & 7.7 & 6 & - & - & - & - \\
\hline Durango & 16.8 & 15.2 & 96.8 & 95.8 & 69.5 & 69.4 \\
\hline Guanajuato & 39.6 & 52 & 93.5 & 66.7 & 84.6 & 88.2 \\
\hline Guerrero & 75.4 & 83.3 & 98.8 & 98.4 & 94.9 & 94.7 \\
\hline Hidalgo & 33.3 & 38.7 & 92.5 & 91.8 & 83.5 & 87.9 \\
\hline Jalisco & 17.6 & 20.2 & 94.2 & 92.6 & 65.1 & 67.4 \\
\hline México & 41.7 & 45.5 & 96.6 & 96.1 & 87.6 & 85.8 \\
\hline Michoacán & 51 & 58.9 & 95.4 & 93.9 & 90.7 & 90.4 \\
\hline Morelos & 38 & 33.7 & 74.4 & 76.5 & 86.9 & 86.8 \\
\hline Nayarit & 14.8 & 17.4 & 90.9 & 87.6 & 79.5 & 79.2 \\
\hline Nuevo León & 4.5 & 9.8 & - & - & 57.6 & 60.8 \\
\hline Oaxaca & 69.4 & 76.7 & 98.2 & 98.1 & 95.4 & 94.9 \\
\hline Puebla & 64.8 & 65.9 & 97.9 & 98.7 & 95.2 & 95.9 \\
\hline Querétaro & 26.2 & 27.8 & 96.8 & 96.4 & 81.8 & 85.6 \\
\hline Quintana Roo & 27.4 & 30.2 & 95.3 & 95.1 & 76.9 & 74.8 \\
\hline San Luis Potosí & 37.6 & 54.2 & 96.2 & 95.9 & 91.1 & 90.6 \\
\hline Sinaloa & 18.6 & 33.7 & 90.1 & 87.5 & 69.7 & 72 \\
\hline Sonora & 10.7 & 11.5 & 77.3 & 72.6 & 50.3 & 51.2 \\
\hline Tabasco & 39.2 & 49 & 88.9 & 85.8 & 88.3 & 89.5 \\
\hline Tamaulipas & 11.6 & 15.4 & - & - & 61.5 & 63.6 \\
\hline Tlaxcala & 55.5 & 49.8 & 100 & 100 & 73.2 & 74.6 \\
\hline Veracruz & 53.7 & 63.6 & 98 & 98.3 & 92.5 & 92.5 \\
\hline Yucatán & 38.2 & 31.2 & 98.2 & 97.4 & 88.6 & 90.5 \\
\hline Zacatecas & 25.4 & 36.5 & - & - & 57.6 & 61.8 \\
\hline
\end{tabular}

Fuente: elaboración propia con base en datos del INEE (2018b): Principales cifras. Educación básica y media superior. Inicio del ciclo escolar 2016-2017. 
Tabla 3. Condiciones de centros preescolares de la zona costa de Chiapas

\begin{tabular}{|c|c|c|c|c|}
\hline Centro & Atención y cuidado infantil & Formación docente & Aspectos legales y normativos & Infraestructura y equipamiento \\
\hline C2 & 55.8 & 0.0 & 38.0 & 28.8 \\
\hline P5 & 54.8 & 25.0 & 62.0 & 55.3 \\
\hline P6 & 48.1 & 47.2 & 56.0 & 12.1 \\
\hline P8 & 50.0 & 52.8 & 54.0 & 37.9 \\
\hline P9 & 62.5 & 38.9 & 60.0 & 54.5 \\
\hline $\mathrm{C}_{10}$ & 62.5 & 38.9 & 52.0 & 30.3 \\
\hline C12 & 55.8 & 41.7 & 44.0 & 27.3 \\
\hline $\mathrm{C}_{13}$ & 57.7 & 61.1 & 76.0 & 21.2 \\
\hline C14 & 38.5 & 38.9 & 56.0 & 18.9 \\
\hline C15 & 42.3 & 41.7 & 62.0 & 33.3 \\
\hline C16 & 38.5 & 27.8 & 60.0 & 31.8 \\
\hline $\mathrm{C}_{17}$ & 34.6 & 0.0 & 42.0 & 10.6 \\
\hline C18 & 67.3 & 63.9 & 92.0 & 39.4 \\
\hline C19 & 55.8 & 33.3 & 80.0 & 27.3 \\
\hline $\mathrm{C} 20$ & 34.6 & 0.0 & 42.0 & 15.2 \\
\hline$C_{21}$ & 78.8 & 50.0 & 92.0 & 48.5 \\
\hline $\mathrm{C}_{22}$ & 51.9 & 55.6 & 64.0 & 25.8 \\
\hline $\mathrm{C}_{23}$ & 66.3 & 52.8 & 68.0 & 39.4 \\
\hline $\mathrm{C}_{24}$ & 59.6 & 50.0 & 68.0 & 36.4 \\
\hline $\mathrm{C}_{25}$ & 57.7 & 44.4 & 44.0 & 31.8 \\
\hline C26 & 53.8 & 61.1 & 72.0 & 22.0 \\
\hline P29 & 53.8 & 55.6 & 72.0 & 36.4 \\
\hline$C_{30}$ & 51.0 & 41.7 & 76.0 & 28.0 \\
\hline$C_{31}$ & 51.9 & 22.2 & 64.0 & 27.3 \\
\hline$C_{31}$ & 50.0 & 16.7 & 44.0 & 16.7 \\
\hline$C_{32}$ & 65.4 & 44.4 & 88.0 & 31.8 \\
\hline $\mathrm{C}_{33}$ & 38.5 & 16.7 & 38.0 & 29.5 \\
\hline$C_{34}$ & 54.8 & 44.4 & 60.0 & 13.6 \\
\hline$C_{35}$ & 49.0 & 33.3 & 60.0 & 30.3 \\
\hline $\mathrm{C}_{36}$ & 48.1 & 27.8 & 40.0 & 12.1 \\
\hline$C_{37}$ & 49.0 & 41.7 & 72.0 & 11.4 \\
\hline $\mathrm{C}_{3} 8$ & 42.3 & 22.2 & 36.0 & 28.8 \\
\hline C39 & 59.6 & 50.0 & 100.0 & 10.6 \\
\hline $\mathrm{C}_{40}$ & 57.7 & 38.9 & 44.0 & 15.2 \\
\hline CE52 & 83.7 & 83.3 & 78.0 & 78.8 \\
\hline $\mathrm{C}_{53}$ & 43.3 & 27.8 & 64.0 & 25.8 \\
\hline P68 & 51.0 & 27.8 & 40.0 & 53.8 \\
\hline P69 & 69.2 & 38.9 & 100.0 & 50.0 \\
\hline
\end{tabular}


Tabla 4. Anexo. Áreas, subáreas e indicadores para la evaluación de centros preescolares

\begin{tabular}{|cc|}
\hline & Atención y cuidado infantil \\
\hline Subárea & Indicador \\
\hline
\end{tabular}

Jornada escolar
complementaria

Atención infantil

Planeación y organización escolar

\section{Retroalimentación de la práctica}

\section{Discapacidad}

Servicios acondicionados a infantes

\section{Vinculación} institucional
Adicional al currículum se ofrecen cursos, charlas, conferencias, talleres para infantes, La institución ofrece clases adicionales organizadas por el mismo centro, La institución ofrece clases adicionales gestionadas por la dependencia a la que pertenece, La institución ofrece jornada ampliada, La institución ofrece actividades extraescolares

Procesos de atención infantil supervisados, Canalización de casos difíciles a profesionales competentes, Uso de actividades lúdicas en el proceso de enseñanza, Consideración de diversidad cultural en el proceso de enseñanza, Atención personalizada a infantes, Hace modificaciones al programa de atención para adaptarlo a infantes, Incluye elementos de su entorno (de cómo viven niñas y niños, con quiénes, etcétera) para atender infantes, Cumplimiento de la jornada laboral

Planificación de actividades, Seguimiento del programa de actividades tal cual está establecido, Diario o registro del propio personal de las jornadas de trabajo, Documentación institucional de las jornadas de trabajo (bitácora institucional), Planeaciones de actividades de atención a infantes, Revisión de contenido de planeaciones, Elaboración de informes sobre la atención, Calendarización de actividades, Archivo digital de registros y datos de infantes, Archivo físico de registros y datos de infantes, Pizarra o similar de avisos para personal, Pizarra o similar de avisos para usuarios, Croquis visible de la distribución de espacios

Retroalimentación de servicio a usuarios (madres, padres o tutores), Retroalimentación de actividades de aprendizaje a usuarios (madres, padres o tutores), Se cuentan las actividades didácticas a usuarios (madres, padres o tutores), Retroalimentación de contenidos de enseñanza a personal, Proporciona informes a usuarios

Baños para uso de personas con capacidades especiales, Espacios acondicionados atención de infantes con Necesidades Especiales, Rampas para personas con sillas de ruedas o con dificultad motriz, Sillas de rueda, Mesas y sillas para la atención de infantes con necesidades especiales

Bebederos, Bebederos colocados a nivel de infantes, Lavamanos, Lavamanos colocados a nivel de infantes, Comedores, Comedores colocados a nivel de infantes, Cambiadores, Tazas de baño adecuados para infantes, Espacios sanitarios organizados por género, Espacios sanitarios exclusivos para personal

Integración de institución a redes que atienden infancia, Vinculación con la sociedad del lugar donde se encuentra la institución, Cooperación con otros centros, Convenios con otras instituciones

\section{Aspectos legales}

Dificultades o controversias legales del centro

Certificación y auditorías del centro

\section{Normatividad jurídica aplicable al centro}

Operación del centro
La institución se encuentra en procesos o controversias legales, El personal encargado observa incongruencias en la normatividad, El personal observa vacíos legales en la legislación que tiene que ver con la institución

Institución certificada, Institución auditada, Información sobre el tipo de certificaciones para la institución, Programas educativos certificados, Procesos de gestión administrativa

Cursos sobre normatividad que tiene que ver con la atención de infantes, Apoyo y orientación legal, Organismos sancionadores, Organismos evaluadores, Normas aplicables por instancias gubernamentales, Normas aplicables por instancias no gubernamentales, Vigilancia en aplicación de derechos 


\section{Formación docente}

Se cuenta con un programa de capacitación, Formación continua, Capacitación al personal,

Formación y capacitación docente

Cultura de evaluación

Profesionalización de personas que atienden infancia
Capacitación frecuente, Capacitación pertinente, Capacitación dirigida a necesidades formativas, Cursos de actualización, Capacitación al personal en primeros auxilios, Capacitación al personal en prevención de riesgos, Capacitación al personal en el manejo de tecnologías informáticas

Evaluación periódica del desempeño del personal, Evaluaciones a usuarios, Evaluación del personal, Evaluaciones psicológicas de personal, Evaluaciones psicológicas de infantes, Instancias monitorean sus actividades

Selección del personal a través de perfiles profesionales, Puestos de trabajo sometidos a concurso, Roles o puestos en la institución sometidos a concurso, Personal construye proyectos, Personal gestiona proyectos, Personal muestra conocimiento de planes o programas de estudio aplicados a la infancia, Personal capacitado para atender a infantes, Elabora materiales didácticos

\section{Infraestructura, equipamiento y financiamiento}

Sanidad al momento de preparar alimentos (usar cubrebocas, cofias, lavarse manos, etc.), Manejo de sustancias o residuos peligrosos, Cercanía con instalaciones que pongan en riesgo seguridad de infantes o personal, Señalamientos viales en la periferia de la institución,

Seguridad, higiene y protección de infantes

Servicios públicos

Comunicación

Áreas de la escuela

Equipamiento para apoyo en la atención

Mantenimiento

Espacios adecuados para la atención infantil

Patrimonio
Señalamiento de sustancias peligrosas, Salidas de emergencia, Escaleras de emergencias, Números de emergencia, Áreas de seguridad, Videocámaras de seguridad al interior de la institución, Videocámaras de seguridad exteriores a la institución, Alarmas de seguridad, Alarma sísmica, Extinguidores, Servicio a extinguidores, Detectores de humo, Suministros y equipo contra incendio, Botiquín de emergencia, Botiquín con utensilios de curación, Puerta principal asegurada o reforzada, Supervisión en preparación de alimentos

Luz eléctrica, Drenaje, Calles pavimentadas en la periferia

Conectividad a internet, Telefonía fija, Telefonía móvil

Sala de juntas, Auditorio, Estacionamiento, Espacios en estacionamiento para personas con capacidades diferentes, Áreas verdes, Espacios para la recreación y el juego, Patio de recreo, Mobiliario para la recreación fuera de aulas (Ej. columpios, resbaladillas, etc.), Áreas para almacenar enseres y material de limpieza, Cocina, Comedores, Sala de recepción

Pizarrones o pintarrones, Mesas y sillas para la atención de infantes, Equipo de cómputo, Proyectores visuales (retroproyectores, cañones), Pantalla para proyecciones visuales, Equipos de audio, Báscula precisa para revisión y seguimiento de peso, Botes de basura, Megáfono u otro aparato de sonido audible en la mayoría de la institución

Pozo de agua propio del cual suministran a la institución, Mantenimiento correctivo de instalaciones, Mantenimiento preventivo de instalaciones, Ventanas con cristales, Portón en buen estado, Puertas en funcionamiento, Conexiones eléctricas adecuadas y estables, Áreas verdes limpias en su totalidad (corte de pasto o zacate, etc.), Aulas climatizadas (aires acondicionados), Climas en funcionamiento, Pintura en buen estado, Materiales para desinfección, Materiales para limpieza, Inmueble limpio y aseado, Recolección de basura, Personal de limpieza

Diseño de instalaciones adecuado a infancia, Adaptación de instalaciones para la atención de infantes

Inmueble propio 